\title{
Performance Improvement of Perturb and Observe Maximum Power Point Tracking Technique for Solar PV Applications
}

\author{
Ihechiluru Fortune Anya ${ }^{1}$, Chitta Saha ${ }^{1}$, Hafiz Ahmed ${ }^{2}$, M. N. Huda ${ }^{1}$, Sujan \\ Rajbhandari $^{1}$
}

\author{
${ }^{1}$ School of Computing, Electronics and Mathematics, Coventry University, Priory Street, \\ Coventry CV1 5FB, UK \\ ${ }^{2}$ School of Mechanical, Aerospace and Automotive Engineering, Coventry University, \\ Priory Street, Coventry CV1 5FB, UK
}

\begin{abstract}
Perturb and Observe Maximum Power Point Tracking (MPPT) is extensively used in charge controllers for extracting maximum power from photovoltaic (PV) module irrespective of irradiance, temperature and load variation. The MPPT technique is mainly used for obtaining the maximum power from the solar PV module and conversion circuit to the load and improving the power quality of PV power generation for grid connection. There are several MPPT methods for example; Perturb and Observe (P\&O) method, Incremental Conductance (IC) method, constant voltage method, etc. The standard P\&O MPPT technique has drawbacks bordering on fast convergence time to maximum power point, poor system response to fast-changing irradiance and steady-state oscillation with fixed step size. This chapter discusses the detailed operation and implementation of an improved $\mathrm{P} \& \mathrm{O}$ algorithm technique to resolve the various challenges of the standard $\mathrm{P} \& \mathrm{O}$ algorithm. This technique segments the operational region of the PV array into four operating sectors and based on the sector location from the maximum power point (MPP), step size modifications are implemented. Furthermore, critical comparison is made between the new P\&O method and the standard P\&O method. Finally, both MPPT algorithms have been implemented in hardware to evaluate their performance and efficiency. The measured results show that the average efficiency of the proposed system is $96.89 \%$ which is more than $4 \%$ higher than the standard system.
\end{abstract}




\section{Introduction}

The global investment in the solar power market has increased ten folds over the last decade and the applications of the photovoltaic (PV) system are becoming important in many countries globally due to the decline in the cost of solar PV modules. However, the performance/efficiency of the PV still is one of the major challenges for researchers and usually depends on the PV module conversion efficiency and the installed site atmospheric condition. The performance is mostly influenced by both external and internal factors such as radiation, wind, electrical losses, structural features, pollution, visual losses, aging, temperature and shading [1-4]. Solar PV demonstrate a nonlinear behaviour and possess a specific position on its characteristic PV curve where the cell extracts maximum power and functions at maximum efficiency. Fig. 1 shows a typical current-voltage (IV) and power-voltage (PV) characteristic curve of a solar PV.

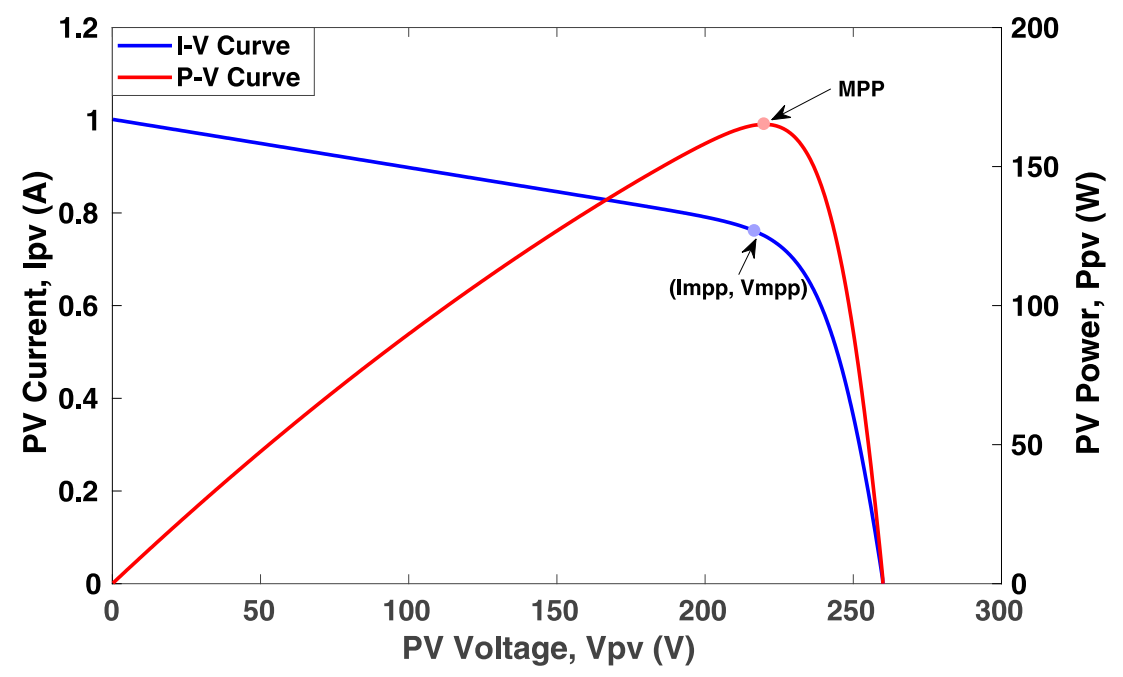

Fig. 1 IV \& PV characteristic curves.

The Maximum Power Point Tracking (MPPT) system is applied to facilitate the delivery of maximum power during the solar PV operation. It tracks the maximum power variations created by the variations in atmospheric conditions and other contributing factors. The MPPT system is essentially a power electronic device introduced between the load and generating source (the solar PV array). The power electronics circuits are operated together with the control algorithm of the MPPT to achieve the extraction of maximum power. Presently, there are several MPPT techniques to extract MPP under uniform irradiance condition (UIC), fast changing irradiance condition (FCIC), and partial shading condition (PSC). The maximum power generation of the solar PV system changes with variations in atmos- 
pheric condition and this influences the electrical characteristics of the load. As a result, the internal impedance of the solar PV system is hardly matched to the impedance of the load. The main purpose of the MPPT is to match the impedance of the solar PV system to the impedance of the load by modifying the converter's duty cycle. Therefore, the (MPP) can be located notwithstanding the unpredictability of the solar PV characteristic curve [5-7]. There are quite a number of MPPT techniques that have been that have been studied to track the solar PV MPP. Ali et al. in [32] compiled a comprehensive review of the most common and efficient MPPT techniques. This has been used to draw a comparative analysis with the proposed system. Authors in [8-10] presented various MPPT techniques covering different necessities according to cost, simplicity, the speed of convergence, tracking efficiency, sensor requirements, operation at steady state, and hardware implementation. The performance of some MPPT techniques supersedes some others for similar operating conditions. Also, Karami et al. and Ezinwanne et al. in $[11,12]$ analysed and conducted a review of energy performance and cost comparison of MPPT techniques and they found that the hybrid MPPT which is a combination of MPPT techniques is more beneficial compared to a single MPPT technique. This would mitigate noise from the extracted power in the event of low irradiance conditions and PSC. The tracking efficiency, dynamic response and steady-state operation of the system are critical areas to be taken into account for a successful MPPT control design when assessing the performance of the modified MPPT system. The MPP needs to be tracked rapidly under UIC, FCIC and PSC. The system tracking efficiency is crucial to assess the success of the MPPT process as it measures the ratio of actual power extracted from the Solar PV to the expected theoretical power expected for a particular period. Eq. (1) is implemented to evaluate the tracking efficiency of the solar PV system [31];

$$
\eta=\frac{1}{s} \sum_{i}^{s} \frac{P_{\text {real }, i}}{P_{\max , i}}
$$

where $P_{\text {real }}$ is the $i^{\text {th }}$ sample of the power measured during Solar PV MPPT implementation, $P_{\max }$ is the $i^{\text {th }}$ sample of the true power expected from the Solar PV under given atmospheric conditions and $s$ being the complete number of samples. A faster tracking speed leads to lower loss in the Solar PV system. Once the MPP has been achieved, the MPPT control algorithm needs to maintain constant operation at this point for the required period. However, this is practically unachievable due nature of perturbation of MPPT algorithms. Nonetheless, the steady state error has to be to the barest minimum [13].

According to the MPPT algorithm classification, there are direct and indirect MPPT techniques. For the direct method which includes Perturb and Observe (P\&O) and Incremental Conductance (InCond.), they implement the system information at a particular period to achieve the MPP [14-18]. The indirect methods (fuzzy logic control, fractional short circuit current, fractional open circuit voltage, 
etc.) rely on the parameters of the system $[19,20]$. The Perturb and Observe (P\&O) method is the most ubiquitous when compared with other methods as a result of its simple operation and low-cost implementation due to the low number of sensors required. Some MPPT methods such as self-oscillation (SO) method, extremum seeking (ES) control, incremental conductance (IC) are derived from $\mathrm{P} \& \mathrm{O}$ technique with variations in implementation of perturbation or the variable observed. The first P\&O MPPT implementation dates back to the 1970s when it was employed for aerospace applications. It has evolved overtime and is presently popular for MPPT. The P\&O MPPT technique exists in two configurations; the duty cycle perturbation where the converter operates in open loop after each perturbation and reference voltage perturbation where the converter is equipped with a feedback voltage loop [34]. The P\&O MPPT is dependent on the step-size. The standard P\&O MPPT implements a specific step-size. So with the application of a large specific step-size, MPP is achieved fast but high steady state oscillations occur. With the application of a small specific step-size, it takes longer time to achieve MPP causing power loss and low steady-state oscillations. Also, with FCIC, the standard P\&O MPPT underperforms with respect to tracking the MPP. Studies have been carried out drawing comparisons between perturbation of voltage and the duty cycle. It has been deduced that with a high rate of voltage perturbation, the system may have poor stability but possesses a faster dynamic response and in comparison, duty cycle displays better stability with poor performance under FCIC [21,22]. Ahmed et al. proposed a modified P\&O MPPT algorithm to decrease the steady-state error and to prevent the loss of direction during tracking. Their technique is further verified with experimental results the measured results show a $1.1 \%$ improvement in tracking efficiency on the standard P\&O MPPT for slow irradiance change and $12 \%$ for FCIC. However, the system response was almost similar to the standard P\&O MPPT showing no improvement [27]. Ahmed and Salam proposed an improved P\&O MPPT algorithm that implements a special control mechanism to change the perturbation size around MPP to reduce the steady state oscillation. It delivers a $2 \%$ improvement in tracking efficiency in comparison to the standard P\&O MPPT. However, the system requires long computational time that impact the response of the controller. Therefore, impeding it from improving the efficiency any further [23]. In [24], a modified P\&O control algorithm has been implemented for a hybrid PV and wind system. The MPPT algorithm tracks power for both generating sources, however, the tracking loop experiences large noise and the system has a significant steady state error which does not aid efficient system operation. In [25], an improved version of P\&O MPPT with a checking algorithm has been proposed. It drastically reduces the dynamic response of the system, and however, there is spike before the power settles at MPP. Also, the perturbation of the duty cycle was high resulting in poor performance under FCIC. Ghassami et al. present a modified P\&O MPPT algorithm to improve the system operation under FCIC. It implements the IV characteristic curve to distinguish the shifting point of operation from the environmental change. The response of the standard P\&O MPPT under FCIC is considerably improved 
on however, high steady state oscillations exist which creates power loss to counter power loss prevented from an improved response time [26].

The evolution of the perturbation process have given rise to another MPPT approach known as Particle swarm optimization (PSO). PSO utilizes low-cost digital controllers and performs well under extreme test conditions [34]. Authors in [35] have demonstrated a hybrid implementation of PSO to track the MPP when the PV module is influenced by partial shading. This implementation combines fuzzy logic control with PSO to properly track the global maximum power point in the system. Fuzzy logic control (FLC) is another recent MPPT technique which does not need any technical knowledge for the PV system and it is known to perform efficiently for fast changing test conditions. Artificial Neural Network(ANN) technique is an intelligent MPPT approach to resolve nonlinear PV characteristic curve. These recent MPPT approaches have their benefits and drawbacks. The $\mathrm{P} \& \mathrm{O}$ has an easy construction and implementation however it experiences oscillations during steady state operation. The IC is better responsive to FCIC than the conventional $\mathrm{P} \& \mathrm{O}$, it is also accurate. However, this accuracy depends on the size of increments. In comparison to recent approaches, PSO has a larger optimization potential that can be achieved in a less complex fashion. However, it can experiences partial optimism that could influence its speed and direction control. FLC is a robust, rapid MPPT approach that yields better stability during various conditions. However, it is expensive, highly complex, and its efficiency is reliant on the accuracy of the rules. The ANN approach can be in various forms. It displays fast tracking speed and yields better stability during various conditions. It is also expensive, highly complex and needs a broad and extensive information about the solar PV parameters.

\begin{tabular}{|llll|}
\hline \multicolumn{2}{|l}{ Nomenclature } & & \\
$N_{p r}$ & parallel connected strings & $N_{s e}$ & series connected strings \\
$I$ & solar PV output current & $I_{P H}$ & light-generated current \\
$I_{s c}$ & short circuit current (A) & $I_{D}$ & diode saturation current \\
$V_{p v}$ & output voltage of solar PV & $V_{o c}$ & open circuit voltage (V) \\
MPPT & Maximum Power Point Tracking & $A$ & Diode ideality factor \\
InCond. & Incremental Conductance & $R_{S}$ & series resistance \\
P\&O & Perturb and Observe & $R_{s h}$ & shunt resistance \\
$q$ & electron charge & $G$ & average solar irradiation \\
FCIC & Fast Changing Irradiance Condition & $K$ & Boltzmann's constant \\
UIC & Uniform Irradiance Condition & $T$ & cell temperature \\
STC & standard test conditions & $\mathrm{BC}$ & Boost Converter \\
\hline
\end{tabular}


In this chapter, an improved efficient variable step $\mathrm{P} \& \mathrm{O}$ algorithm is proposed to improve system dynamic response, decrease the steady-state oscillations and improve the system behaviour during FCIC. This method involves the segmentation of the PV array characteristic curve into different operating segments. As a result of this segmentation, the system is subject to step-size modifications based on the segment location from MPP. With the operating point far from the MPP, large-step voltage size is employed for the perturbation of reference voltage to improve system response and on the other hand, large-step voltage size is employed with the operating point near the MPP. This algorithm presents a fast and stable MPPT technique, which tracks the MPP at various atmospheric conditions with a low number of sensors. The proposed system is simulated on MATLAB/Simulink environment and experimented using the laboratory scale solar development system.

\section{System Configurations}

The Solar PV system has the PV cell as its basic constituent. PV cells are connected in series and/or parallel into what is called a PV module and PV modules are wired in series and/or parallel to build a PV Array. The I-V relationship is as given by [28];

$$
I=N_{p r} I_{P H}-N_{p r} I_{D}\left[\exp \left(\frac{q\left\{V_{p v}+I R_{s}\right\}}{N_{s e} K A T}\right)-1\right]-\frac{V_{p v}+I R_{s}}{R_{s h}}
$$

where the parameters are described under the nomenclature. The Irradiance, $G$ and Temperature, $T$ influence the light generated current, $I_{P H}$.

Table 1. Solar PV module Characteristics

\begin{tabular}{ll}
\hline Maximum Power & $165 \mathrm{~W}$ \\
Voltage at Maximum Power & $220 \mathrm{~V}$ \\
Current at Maximum Power & $0.75 \mathrm{~A}$ \\
Open Circuit Voltage & $260 \mathrm{~W}$ \\
Short Circuit Current & $1 \mathrm{~A}$ \\
\hline
\end{tabular}

In [28], the interrelation of subsidiary parameters to the parameters in Eq. (2) has been fully expressed. See Table 1 for Solar PV output characteristics for the standard test conditions (STC). The STC of a photovoltaic module is a test performed at irradiation of $1000 \mathrm{~W} / \mathrm{m}^{2}$, a temperature of $25^{\circ} \mathrm{c}$ and an air mass of 1.5 (which is the equivalent for Europe) in order to have a uniform test condition of the PV modules thereby making it possible in conducting uniform comparison of PV modules made by different manufacturers. Figs. 2 and 3 demonstrate the solar 
IV and PV characteristic with the variation of irradiation and temperature. As stated, the DC/DC converter (boost converter) serves as an interface between the solar PV and the load. It steps up the voltage, $V_{p v}$ from the solar PV to an output, according to Eq. (3) based on the duty cycle, $D$ which is set to 0 for an open switch and 1 for a closed switch.

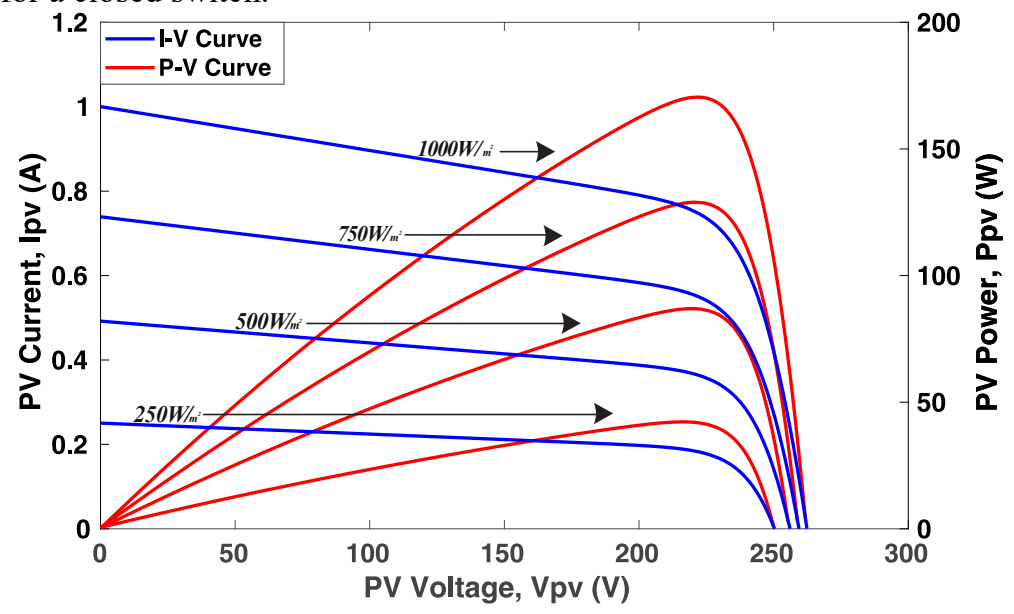

Fig. 2 Solar IV and PV Characteristic Curves for Irradiation variation at $25^{\circ} c$.

$$
V_{o u t}=\frac{V_{p v}}{1-D}
$$

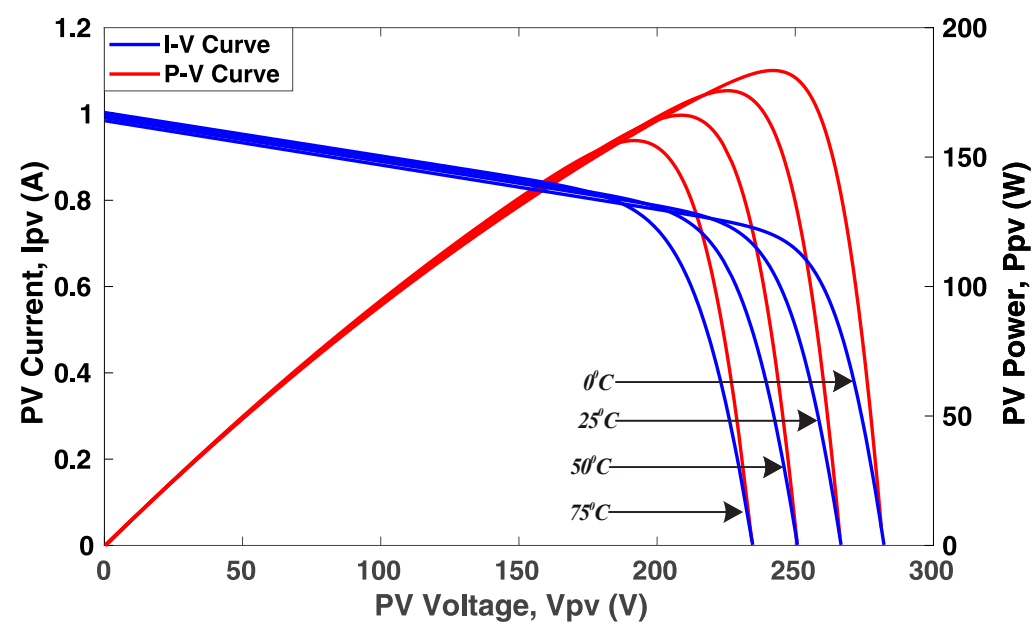

Fig. 3 Solar IV and PV Characteristic Curves for Temperature Variation at $1000 \mathrm{~W} / \mathrm{m}^{2}$. 


\section{P\&O MPPT Algorithms}

The definition of the standard P\&O MPPT algorithm clearly indicates that the output power variation at the peak point of the PV characteristic curve would be zero $\left(\Delta P_{p v}=0\right)$. The algorithm functions by performing perturbation (rising and declining) at the voltage of the solar PV and evaluates the resulting power $P_{(n)}$ to the initial power before perturbation $P_{(n-1)}$. When observed, if there is an increase in the Solar PV power $\left(\Delta P_{p v}>0\right)$ after perturbation, the process of perturbation should continue in the same direction else transposed to the reverse. The process of perturbation is performed recurrently until MPP is achieved at $\left(\Delta P_{p v}=0\right)$. The standard $\mathrm{P} \& \mathrm{O}$ algorithm can be implemented where a reference voltage, $V_{\text {ref }}$ is essentially the tool for perturbation. The $V_{r e f}$ is compared with $V_{p v}$ and an error signal is achieved. This is fed to a proportional integral (PI) controller which appropriately determines the proportional gain, $K_{p}$ and integral gain, $K_{i}$ to deliver a desired response. Once the PV output power is fed to the boost converter, PI controller functions by regulating the duty cycle. Also, the duty cycle can be the perturbation tool and the power can be observed and computed at every pulse width modulation (PWM) cycle [29].

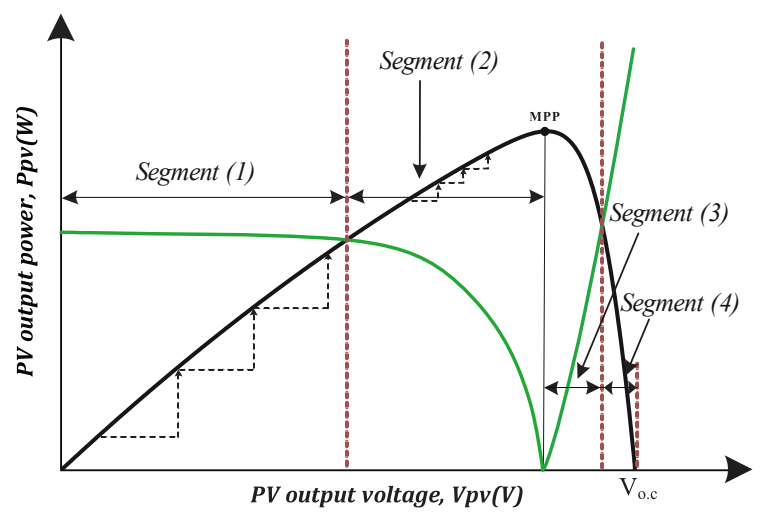

Fig. 4 Proposed P\&O MPPT concept.

The step-size determines the amplitude of steady-state oscillations at the MPP and the standard P\&O algorithm typically implements a fixed step size. With a small step size, there is a trade-off as the steady-state oscillations are at the barest minimum but the dynamic response of the system to achieve MPP is slow and a longer time is taken to achieve MPP. Alternatively, a large step size, increase the response of the system to achieve MPP and less time is taken to achieve MPP. However, there is a considerable increase in the steady-state oscillation $[21,22]$. The proposed $\mathrm{P} \& \mathrm{O}$ algorithm splits the PV characteristic curve operational region into four segments as exhibited in Fig. 4. This permits the implementation of variable 
step size depending on the distance between the operating point and the MPP. With a long distance from the MPP (segments 1 and 4), a large step size is implemented to decrease the response time and cause less time to be taken to achieve MPP. With a close distance to the MPP (segments 2 and 3) a small step size is implemented to lessen the steady state oscillations at the MPP. Fig. 5 illustrates the flow diagram for the proposed $\mathrm{P} \& \mathrm{O}$ algorithm. This approach eliminates the high steady state oscillation accompanied with a large step size and it mitigates the poor response of the system which creates a longer period to track the MPP due to a small step size. It also efficient tracking during FCIC.

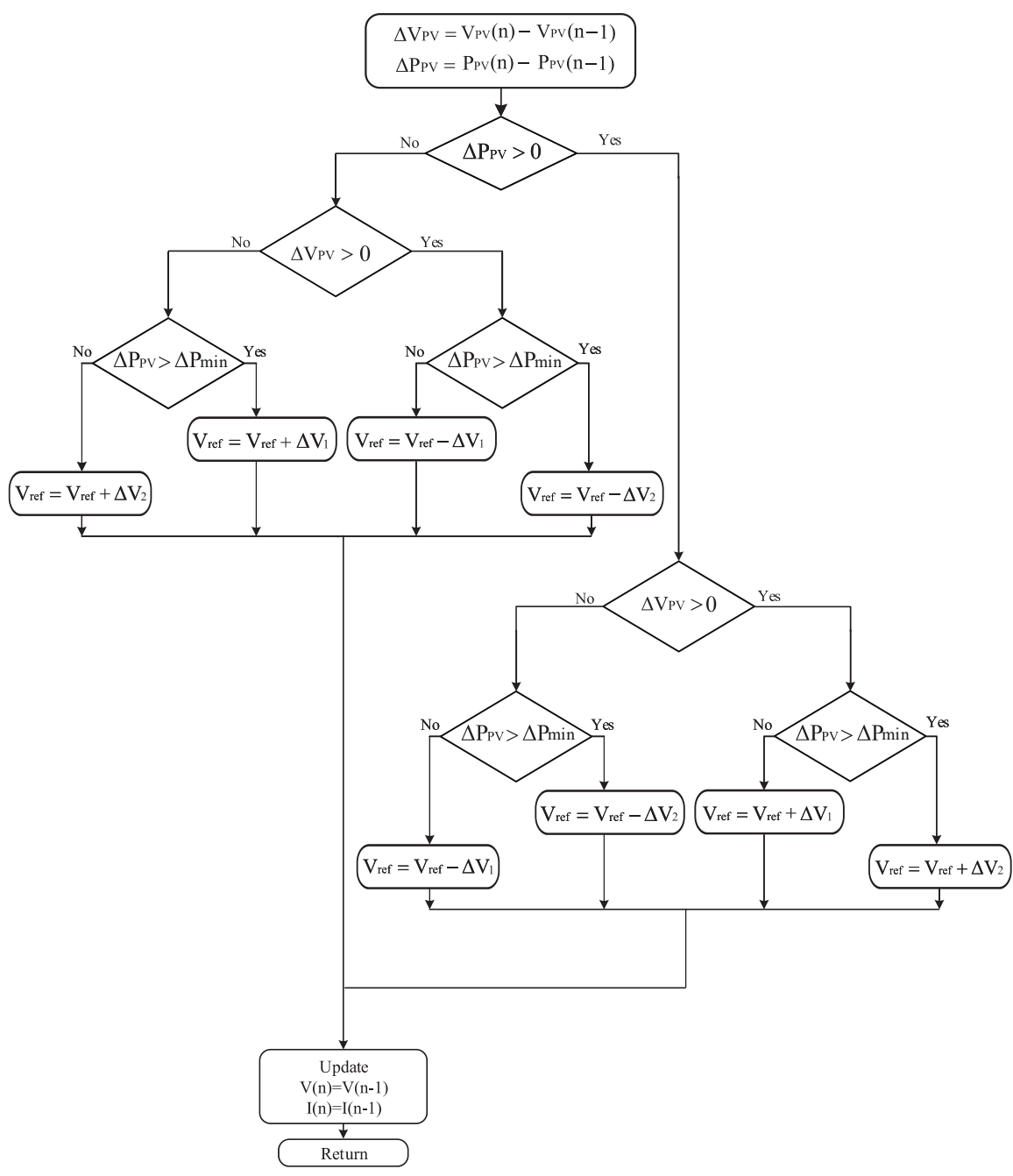

Fig. 5 The flow diagram of the proposed P\&O MPPT Algorithm. 


\section{Simulation and Experiment}

The performance of a stand-alone solar PV system based on the above described system is simulated in the MATLAB/Simulink environment. This comprises of a boost converter placed in between solar PV array and a resistance to serve as a load. A MOSFET gate signal controls the converter with a switching frequency of $10 \mathrm{kHz}$. Capacitors and an inductor rating of $100 \mu \mathrm{f}$ and $3 \mathrm{mH}$ were implemented for filtering. Large step size of 0.01 and small step size of 0.0001 have been implemented for the $\mathrm{P} \& \mathrm{O}$ procedure. For stable operation, these parameters have been achieved from evaluating the boost converter topology based on the system power specifications. To verify the performance of the proposed system over the standard system, a rigorous profile of extreme atmospheric conditions were considered. Firstly, tests were performed on the standard and proposed systems under STC for UIC. Further tests were performed on step changing irradiance and FCIC under the standard temperature of $25^{\circ} \mathrm{C}$. The step changing irradiance profile is illustrated in Fig. 9 and the FCIC is as illustrated in Fig. 13 [30, 31]. The tests were carried out for $1 \mathrm{~s}$ duration.

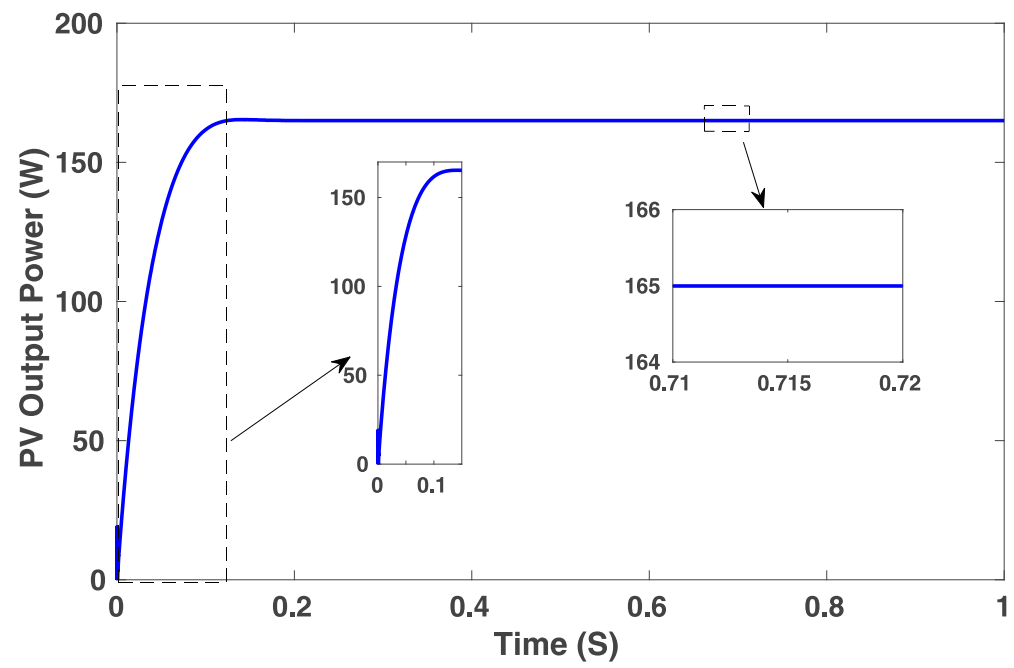

Fig. 6 Output power for small step size standard P\&O system.

Fig. 6 illustrates the solar PV output power for a small step size under UIC. The results display no oscillations at the MPP. However, the system MPP tracking performance is poor as it takes $100 \mathrm{~ms}$ to achieve MPP. Fig. 7 illustrates the solar PV output power for a large step size under UIC. From the zoomed areas, it displays improved MPP tracking performance with a response time under $10 \mathrm{~ms}$ to achieve MPP. However, large steady state oscillations exist around the MPP with a peak difference of $1 \mathrm{~W}$ which eventually influences the solar PV output power. Fig. 8 il- 
lustrates the solar PV output power for the proposed system under UIC. It is evident from the zoomed areas that the proposed system improves the time to track MPP and minimizes the steady-state oscillations. Thus, bringing together the benefits of small and large step size systems and improving on their shortcomings.

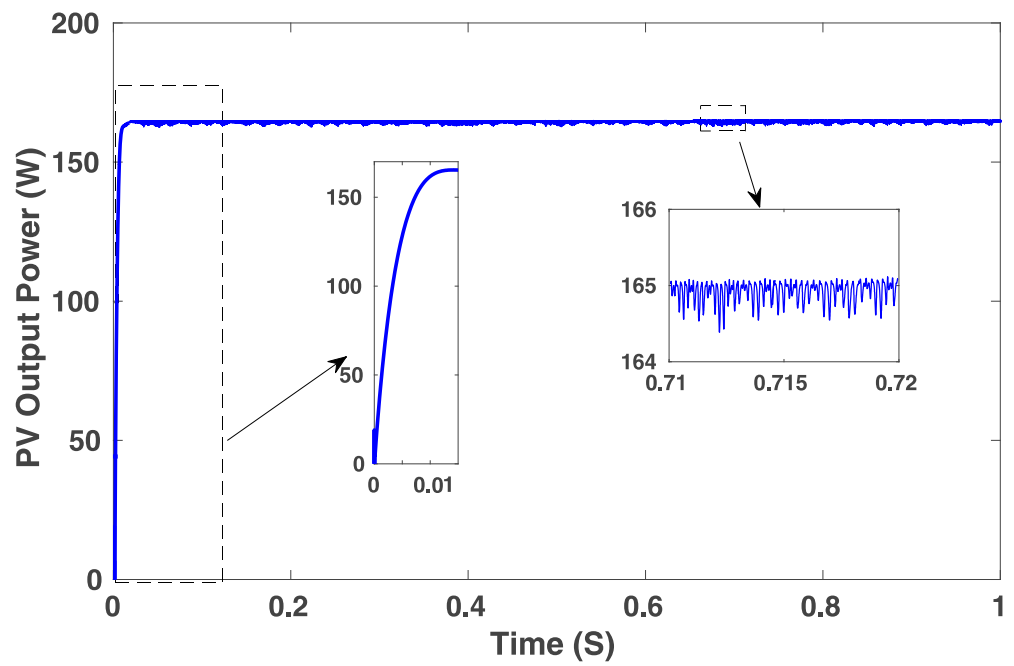

Fig. 7 Output power for large step size standard P\&O system.

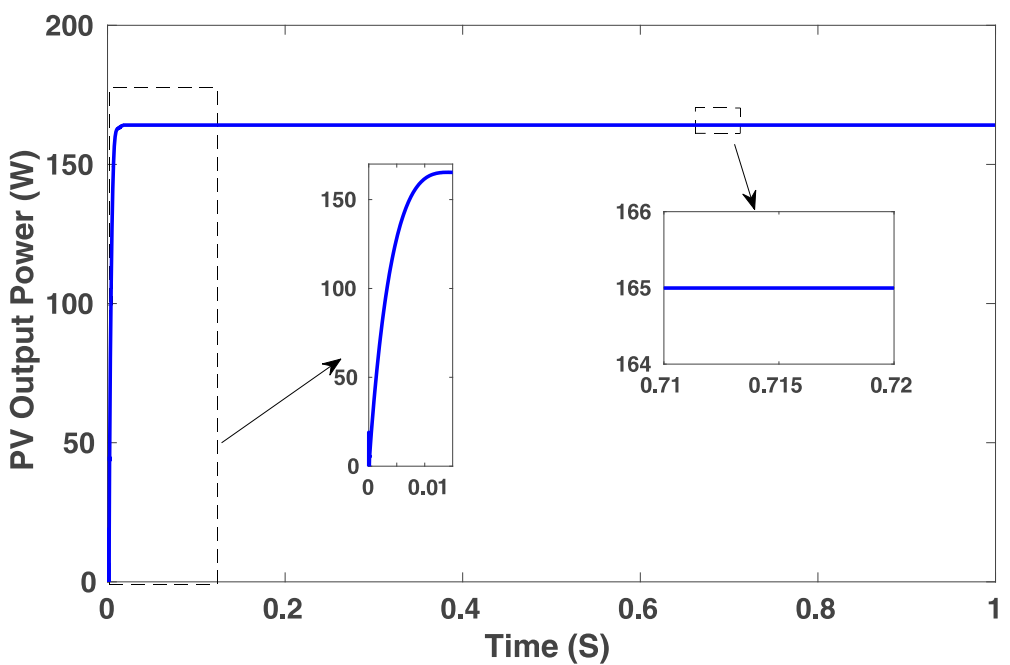

Fig. 8 Output power for Proposed P\&O system. 


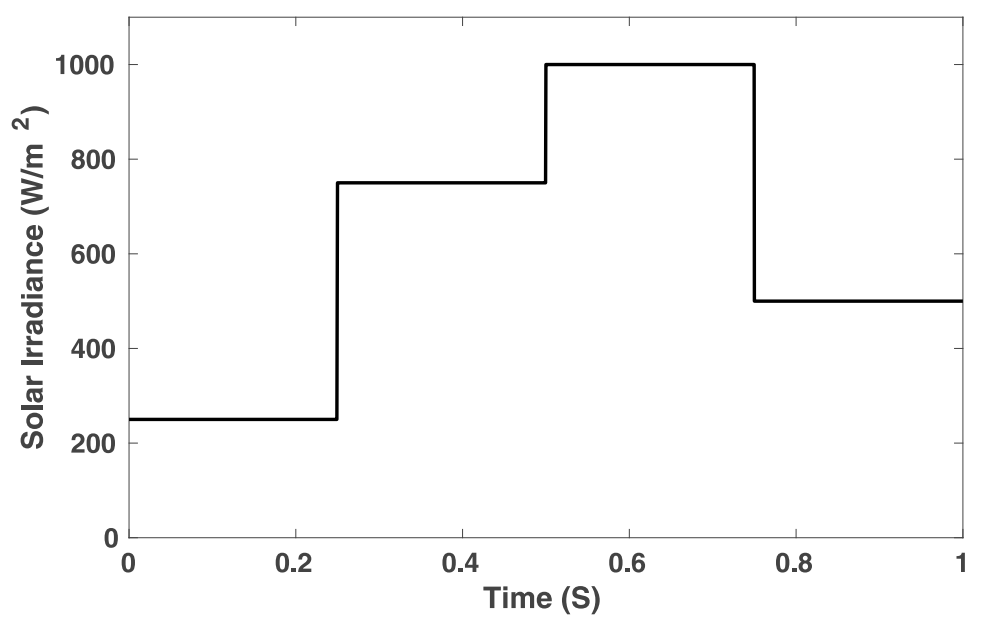

Fig. 9 Step changing irradiance profile [30].

The results of the test performed under the step changing irradiance profile on the small step size and large step size standard and the proposed P\&O MPPT systems are illustrated in Figs. 10-12. The small step size system takes a longer time to achieve MPP for the different irradiances. For $250 \mathrm{~W} / \mathrm{m}^{2}$, it takes $30 \mathrm{~ms}$ to settle at an MPP of $44.64 \mathrm{~W}$. To get to $750 \mathrm{~W} / \mathrm{m}^{2}$, it takes $90 \mathrm{~ms}$ to settle at MPP. To get to $1000 \mathrm{~W} / \mathrm{m}^{2}$, it takes $100 \mathrm{~ms}$ to settle at MPP. In the same way, the large step size system has a better tracking ability and achieves MPP in less time.

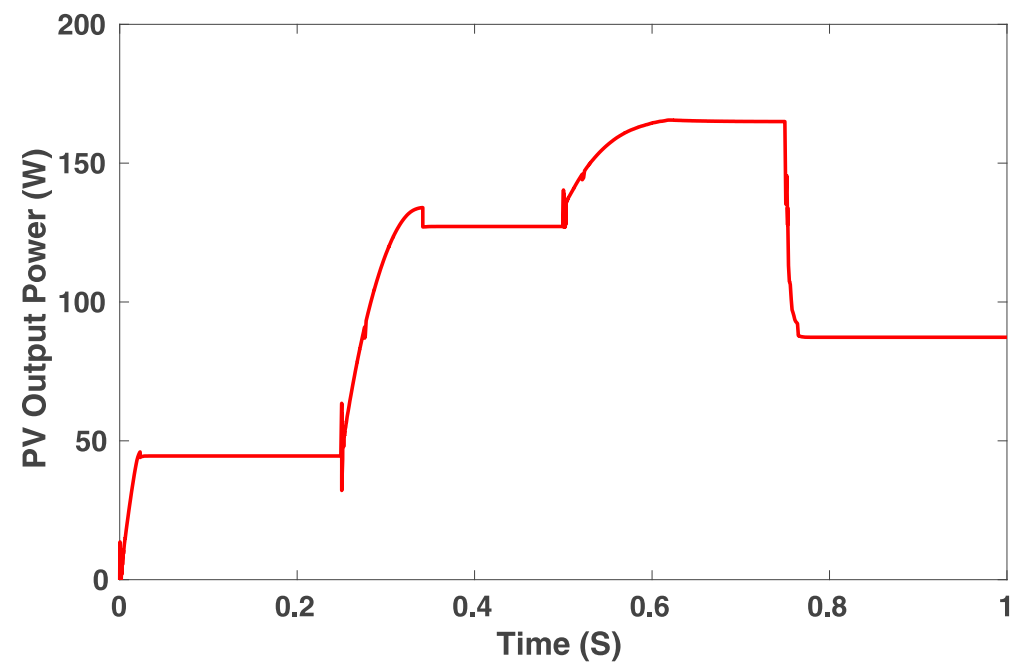

Fig. 10 Output power for small step size standard P\&O system under step changing Irradiance. 


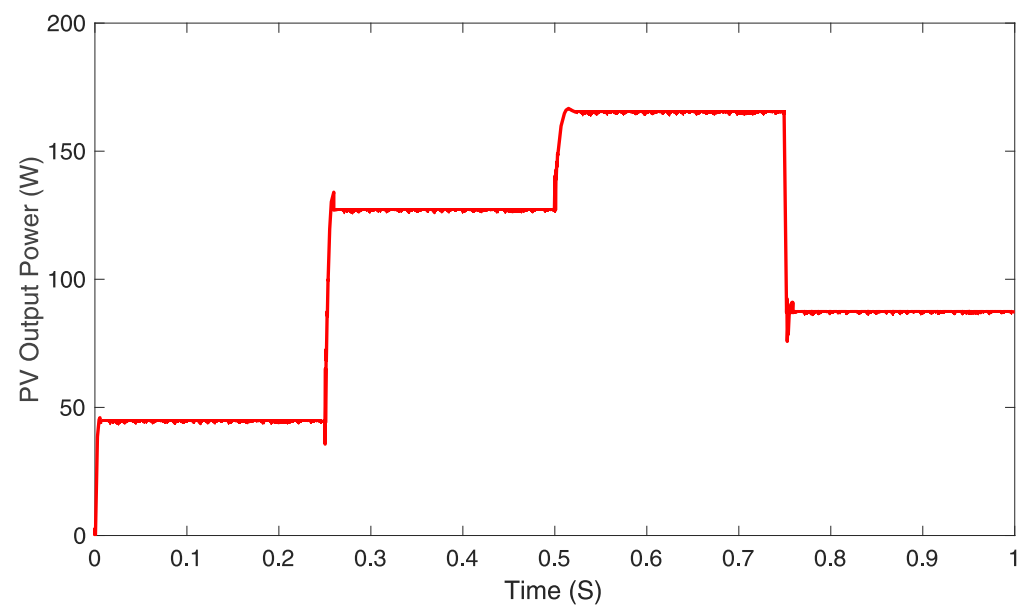

Fig. 11 Output power for large step size standard P\&O system under step changing Irradiance.

However, it displays high steady state oscillations with a peak difference of $1 \mathrm{~W}$. The proposed system as illustrated in Fig. 12 improves the time to track MPP and minimizes the steady-state oscillations. It clearly combines the advantages of small and large step size systems and prevents the disadvantages attached to them.

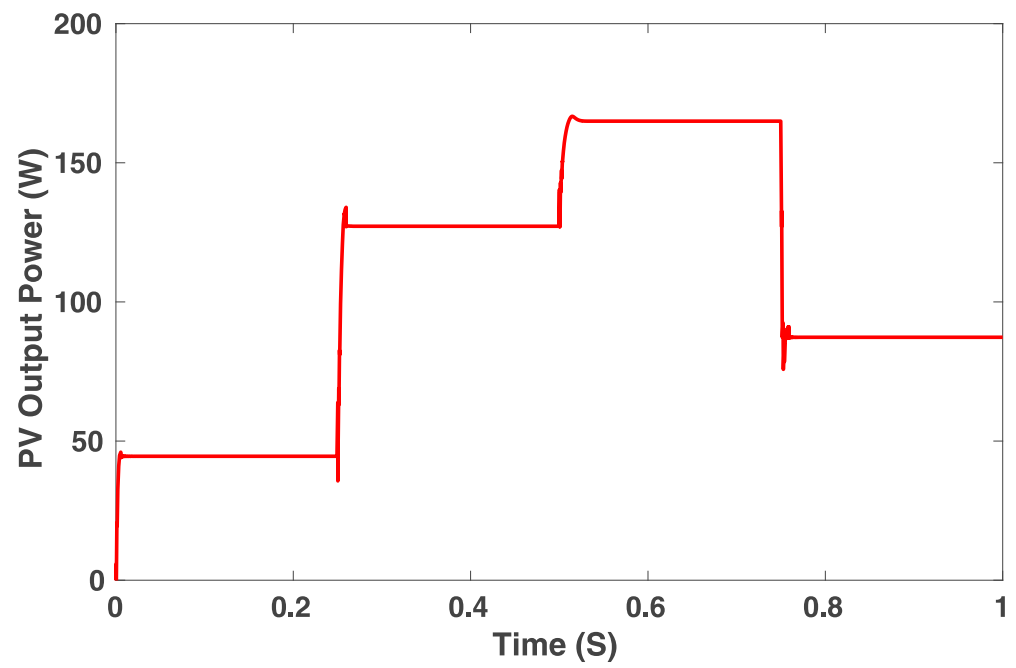

Fig. 12 Output power for Proposed P\&O system under step changing Irradiance.

Fig. 14 illustrates the comparison between the theoretical results for solar PV output power standard $\mathrm{P} \& \mathrm{O}$ and Proposed $\mathrm{P} \& \mathrm{O}$ system output power. It is evident 
that the proposed system performs better than the standard one. The standard system performs poorly for decreasing solar irradiance when the solar irradiance drop is steep. This is typical as the standard system loses direction when tracking MPP for FCIC. This poor performance is corrected with the proposed system.

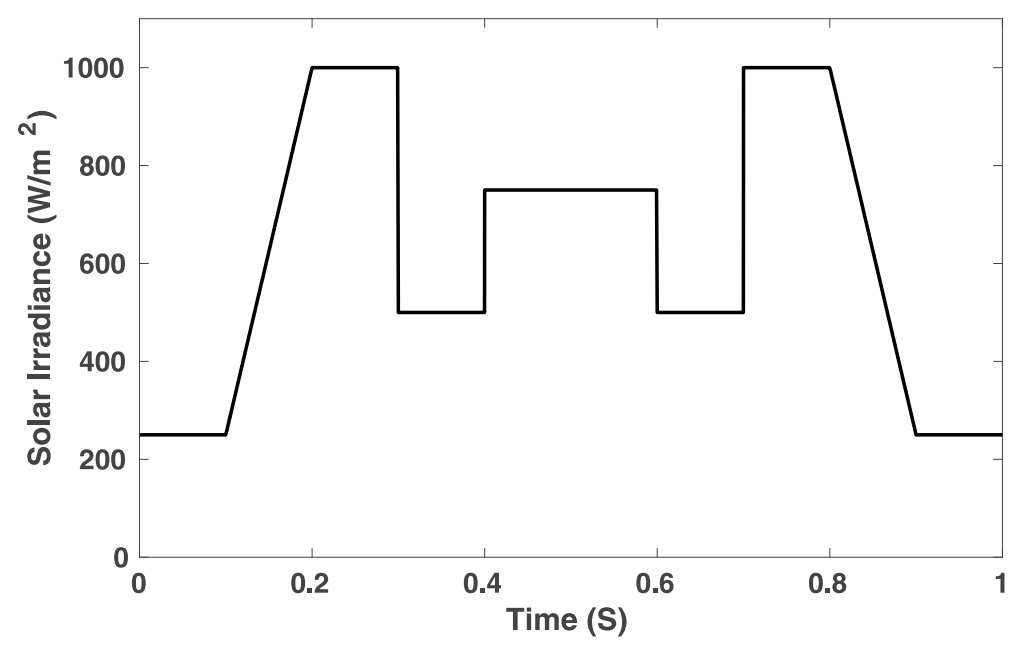

Fig. 13 Fast-changing irradiance profile [31].

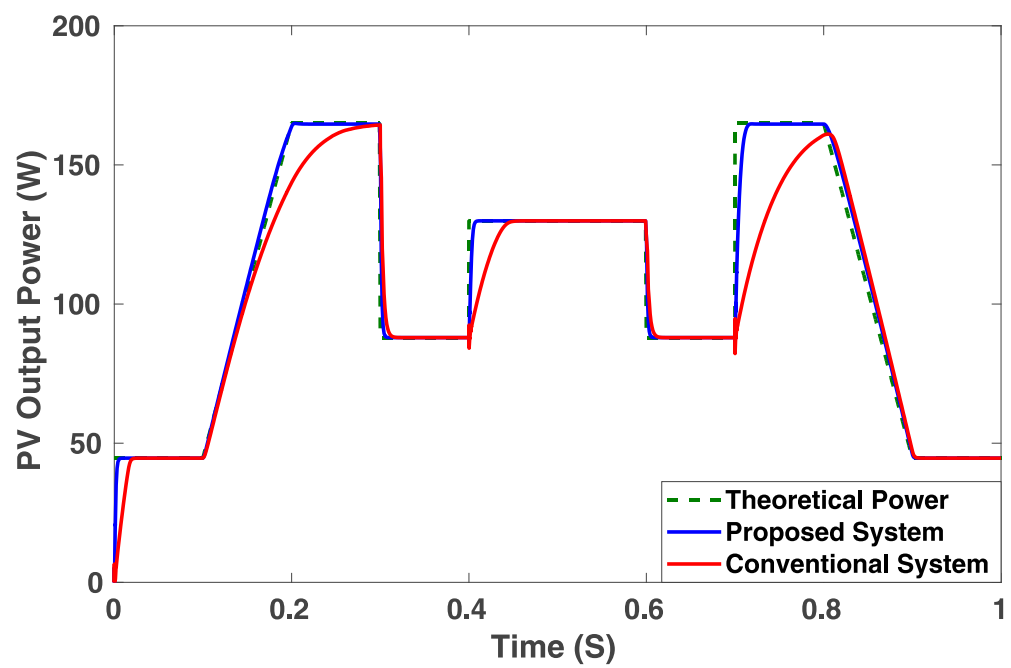

Fig. 14 Solar PV output power under step changing Irradiance. 


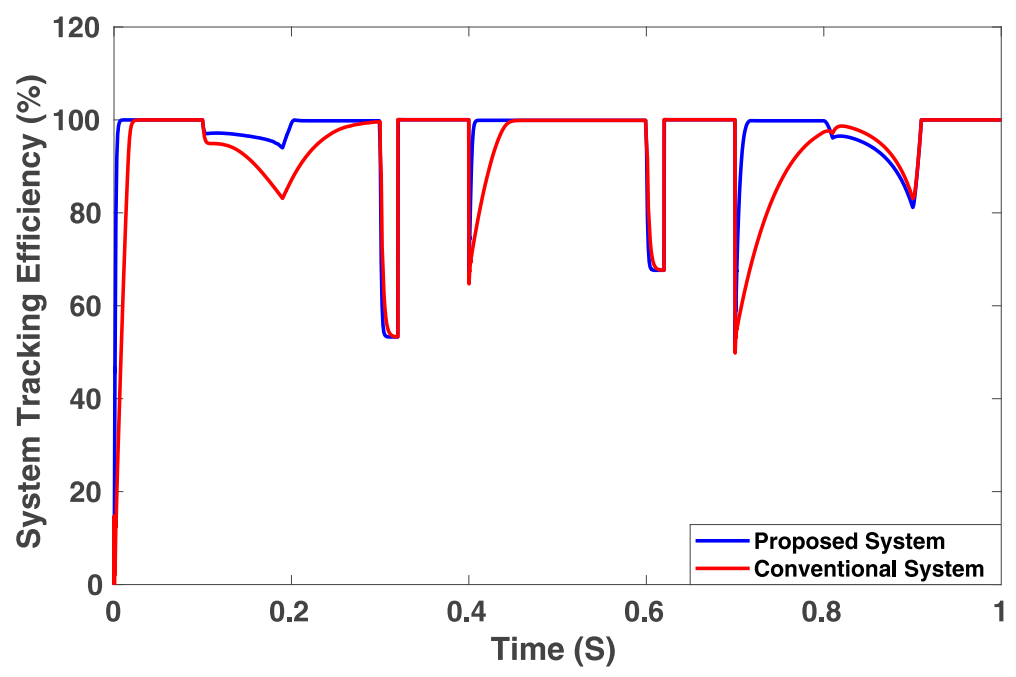

Fig. 15 Solar PV Tracking Efficiency.

Fig. 15 illustrates the tracking efficiency of the standard and the proposed $\mathrm{P} \& \mathrm{O}$ system for the solar irradiance profile in Fig. 13 and this is calculated from Eq. (1). From the result in Fig. 19, the proposed system is more efficient. The average efficiency for the standard system is $92.55 \%$ and that of the proposed system is $96.89 \%$. There is, therefore, an improvement of over $4 \%$.

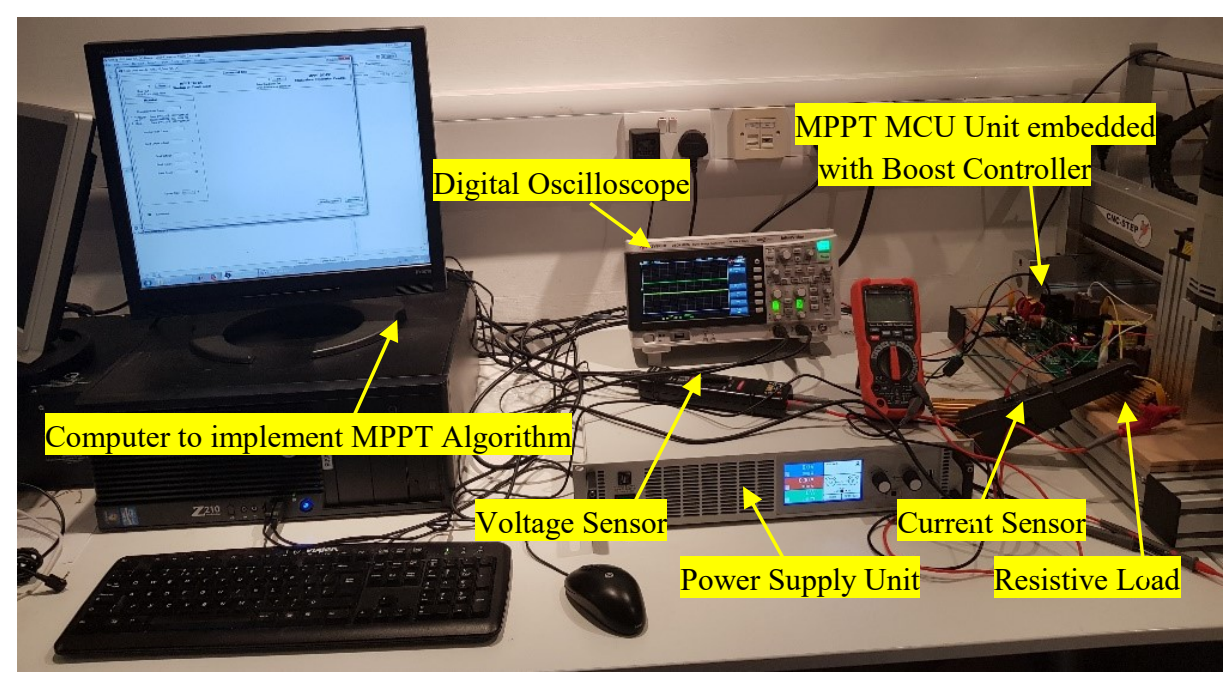

Fig. 16 MPPT Hardware Implementation Setup 


\begin{tabular}{|c|c|c|c|c|c|}
\hline \multicolumn{6}{|c|}{ Comparative Analysis of P\&O MPPT Techniques } \\
\hline $\begin{array}{l}\text { Evaluated } \\
\text { Parameters }\end{array}$ & $\begin{array}{l}\text { Proposed } \\
\text { Method }\end{array}$ & [33] & [15] & {$[14]$} & [27] \\
\hline Set-up & $\begin{array}{l}\text { Standalone } \\
\text { PV }\end{array}$ & $\begin{array}{l}\text { Standalone } \\
\text { PV }\end{array}$ & $\begin{array}{l}\text { Standalone } \\
\text { PV }\end{array}$ & $\begin{array}{l}\text { Standalone } \\
\text { PV }\end{array}$ & $\begin{array}{l}\text { Standalon } \\
\text { e PV }\end{array}$ \\
\hline Converter & Boost & Buck- boost & Boost & Boost & $\begin{array}{l}\text { Buck- } \\
\text { Boost }\end{array}$ \\
\hline $\begin{array}{l}\text { Tracking } \\
\text { Method }\end{array}$ & $\begin{array}{l}\text { Variable } \\
\text { step-size } \\
\text { based on en- } \\
\text { gendered } \\
\text { curve }\end{array}$ & $\begin{array}{ll}\text { Fixed step- } \\
\text { size }\end{array}$ & $\begin{array}{l}\text { Variable } \\
\text { step-size }\end{array}$ & $\begin{array}{l}\text { Confined } \\
\text { search } \\
\text { space }\end{array}$ & $\begin{array}{l}\text { Adaptive } \\
\text { step-size }\end{array}$ \\
\hline $\begin{array}{l}\text { Applica- } \\
\text { tion }\end{array}$ & $\begin{array}{l}\text { UIC and } \\
\text { FCIC }\end{array}$ & $\begin{array}{l}\text { Ramp Pro- } \\
\text { file }\end{array}$ & Step Profile & $\begin{array}{l}\text { UIC and } \\
\text { FCIC }\end{array}$ & FCIC \\
\hline $\begin{array}{l}\text { Simulation } \\
\text { or Experi- } \\
\text { ment }\end{array}$ & Both & Simulation & Simulation & Both & Both \\
\hline $\begin{array}{l}\text { Conclu- } \\
\text { sions }\end{array}$ & $\begin{array}{l}\text { Improved Ef- } \\
\text { ficiency for } \\
\text { UIC and } \\
\text { FCIC. }\end{array}$ & $\begin{array}{l}\text { Poor per- } \\
\text { formance at } \\
\text { low Irradi- } \\
\text { ance. }\end{array}$ & $\begin{array}{l}\text { Steady state } \\
\text { Oscillation } \\
\text { reduced but } \\
\text { displays } \\
\text { poor initial } \\
\text { response. }\end{array}$ & $\begin{array}{l}\text { Reduced re- } \\
\text { sponse } \\
\text { time, im- } \\
\text { proved } \\
\text { steady state } \\
\text { operation. }\end{array}$ & $\begin{array}{l}\text { Improved } \\
\text { steady } \\
\text { state oper- } \\
\text { ation and } \\
\text { efficiency } \\
\text { for FCIC. }\end{array}$ \\
\hline
\end{tabular}

The performance of the standard P\&O MPPT algorithm and the proposed P\&O MPPT algorithm were experimentally evaluated. Fig. 16 shows the system set up for experimental implementation of the solar PV system. The test bench comprises of a Digitally Controlled HV Solar MPPT DC-DC Converter Using Texas Instrument C2000 Piccolo Microcontroller unit (MCU), current and voltage sensors, PV power supply unit, digital oscilloscope, resistive load, and a computer for MPPT implementation. For the duration of UIC, the PV power supply unit provides uniform irradiance at a set percentage equivalent to $1000 \mathrm{~W} / \mathrm{m}^{2}$. The PV panel output voltage and current are measured and then the measured values are used to compute the required power by the MPPT algorithm. $V p v$ is applied to the boost controller of the MCU, the hardware is regulated by the MCU by implementing 4 PWM outputs and 3 feedback signals. The feedback signals implement the control loops of the voltage and current for the boost controller. The PV panel provides an output voltage of $220 \mathrm{~V}$ with an output current of $0.75 \mathrm{~A}$ and the boost controller produces an output voltage of approximately $403 \mathrm{~V}$. The switch PWM signals minimize the ripple in the PV panel current. The MPPT algorithm is responsible for determining a set reference $V_{p v_{-} \text {ref }}$ for the $V_{p v}$ by implementing a control system to regulate $V_{p v}$ when it goes over or under the $V_{p v_{-} r e f}$. The resistive load is connect- 
ed to the output of the boost converter and draws a current of $0.41 \mathrm{~A}$. Another test is also performed on step changing irradiance and the results are as illustrated in Figs. 17-19.

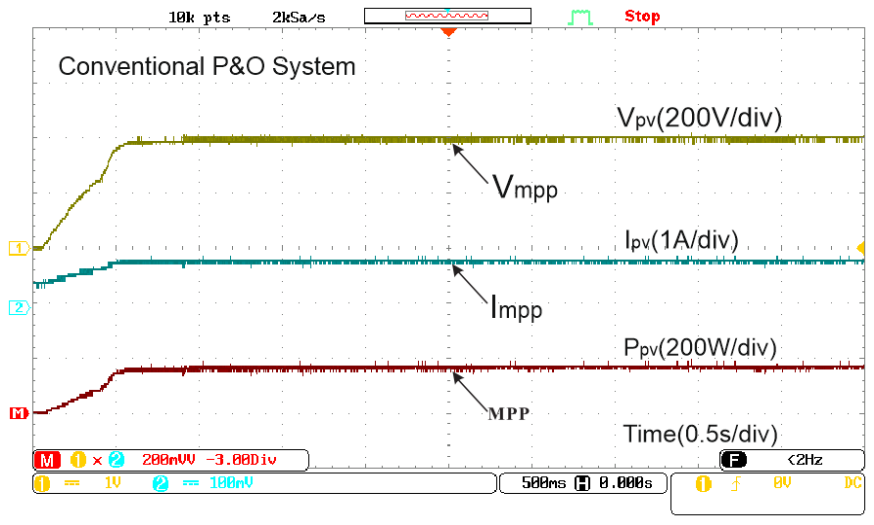

Fig. 17. The measured waveforms $\left(V_{p v}, I_{p v}, P_{p v}\right)$ versus time for standard $\mathrm{P} \& \mathrm{O}$ MPPT under UIC.

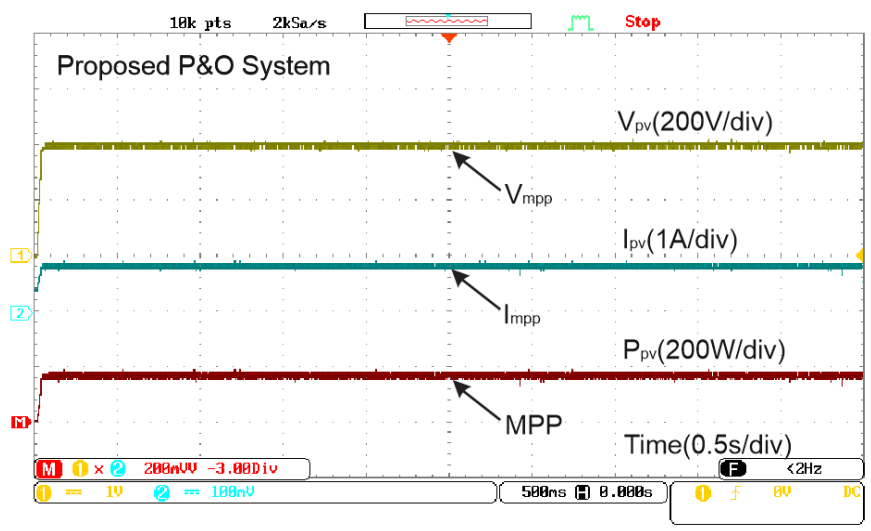

Fig. 18. The measured waveforms $\left(V_{p v}, I_{p v}, P_{p v}\right)$ versus time for proposed $\mathrm{P} \& \mathrm{O}$ MPPT under UIC.

In Figs. 17 and 18, the results for the hardware implemented PV system can be seen under UIC. This shows that the P\&O gets to the appropriate MPP which is $165 \mathrm{~W}$. The proposed $\mathrm{P} \& \mathrm{O}$ system has a tracking ability that is better than that of the standard $\mathrm{P} \& \mathrm{O}$ system as the standard $\mathrm{P} \& \mathrm{O}$ system takes $0.5 s$ to achieve MPP as against $0.02 s$ by the proposed $\mathrm{P} \& \mathrm{O}$ system. Fig. 19 illustrates the tracking ability of the proposed $\mathrm{P} \& \mathrm{O}$ system under step changing irradiance. This has been achieved by varying the irradiance from $1000 \mathrm{~W} / \mathrm{m}^{2}$ to $500 \mathrm{~W} / \mathrm{m}^{2}$ to $1000 \mathrm{~W} / \mathrm{m}^{2}$. 
From the results, the system performs properly as it tracks the MPP of $88 \mathrm{~W}$ at 500 $\mathrm{W} / \mathrm{m}^{2}$ and is capable of regaining the original MPP of $165 \mathrm{~W}$ at $1000 \mathrm{~W} / \mathrm{m}^{2}$.

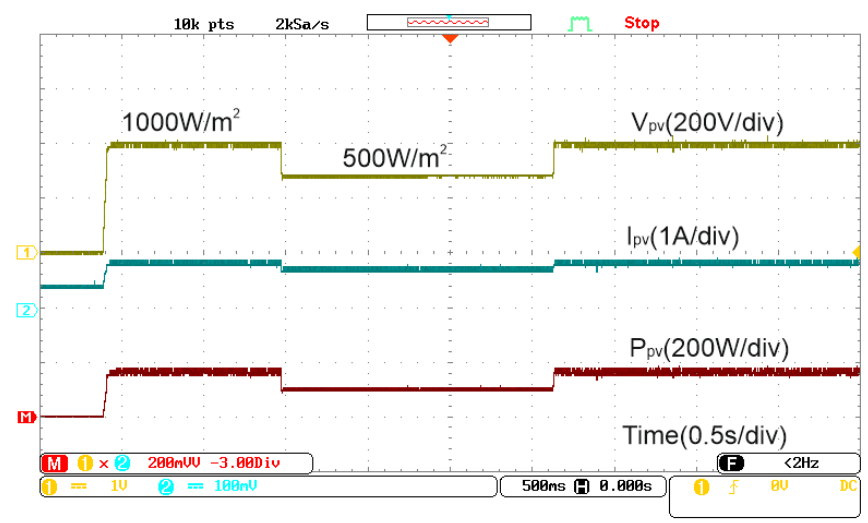

Fig. 19. The measured waveforms $\left(V_{p v}, I_{p v}, P_{p v}\right)$ versus time for proposed $\mathrm{P} \& \mathrm{O}$ MPPT under Step Changing Irradiance.

\section{Conclusions}

In this chapter, an improved $\mathrm{P} \& \mathrm{O}$ algorithm has been proposed to enhance the dynamic response, MPP tracking capacity and decrease the steady-state oscillations at the MPP of a solar PV system and improve its behaviour during certain atmospheric conditions. This system splits the PV characteristic curve into segments and carries out a multi-segment variable size control system of variation of the voltage step size. The proposed algorithm is simulated on MATLAB/Simulink and experimented with a laboratory scale solar development system. The tracking efficiency of the proposed system, as well as its performance, are evaluated with the standard $\mathrm{P} \& \mathrm{O}$ system. The results show a significant improvement from the proposed system on the solar PV system dynamic response, the steady-state oscillations, thereby improving the overall efficiency and outperforming the standard system under various atmospheric conditions.

\section{References}

[1] United Nations Environment Programme [Ed.] Frankfurt School of Finance and Management and Bloomberg New Energy, "Global Trends in Renewable Energy investment,” p. 84, 2016. 
[2] S. A. M. Said, G. Hassan, H. M. Walwil, and N. Al-Aqeeli, "The effect of environmental factors and dust accumulation on photovoltaic modules and dustaccumulation mitigation strategies," Renew. Sustain. Energy Rev., vol. 82, pp. 743-760, Feb. 2018.

[3] S. Verma and H. K. Verma, "Modeling \& Analysis of Standalone Photovoltaic System," no. 2, pp. 259-265, 2013.

[4] S. A. Sulaiman, A. K. Singh, M. M. M. Mokhtar, and M. A. Bou-Rabee, "Influence of Dirt Accumulation on Performance of PV Panels," Energy Procedia, vol. 50, pp. 50-56, 2014.

[5] J. M. Enrique, J. M. Andújar, and M. A. Bohó Rquez, "A reliable, fast and low cost maximum power point tracker for photovoltaic applications," Sol. Energy, vol. 84, pp. 79-89, 2009.

[6] L. Liu, X. Meng, and C. Liu, "A review of maximum power point tracking methods of PV power system at uniform and partial shading," Renew. Sustain. Energy Rev., vol. 53, pp. 1500-1507, 2015.

[7] F. Belhachat and C. Larbes, "A review of global maximum power point tracking techniques of phBelhachat, F. and Larbes, C. (2018) 'A Review of Global Maximum Power Point Tracking Techniques of Photovoltaic System under Partial Shading Conditions'. in Renewable and Sustainable Energy R," Renewable and Sustainable Energy Reviews, vol. 92. pp. 513-553, Sep-2018.

[8] D. Verma, S. Nema, A. M. Shandilya, and S. K. Dash, "Maximum power point tracking (MPPT) techniques: Recapitulation in solar photovoltaic systems," Renew. Sustain. Energy Rev., vol. 54, pp. 1018-1034, 2015.

[9] J. P. Ram, T. S. Babu, and N. Rajasekar, "A comprehensive review on solar PV maximum power point tracking techniques," Renew. Sustain. Energy Rev., vol. 67, pp. 826-847, Jan. 2017.

[10] M. A. M. Ramli, S. Twaha, K. Ishaque, and Y. A. Al-Turki, "A review on maximum power point tracking for photovoltaic systems with and without shading conditions," Renew. Sustain. Energy Rev., vol. 67, pp. 144-159, Jan. 2017.

[11] N. Karami, N. Moubayed, and R. Outbib, "General review and classification of different MPPT Techniques,” Renew. Sustain. Energy Rev., vol. 68, no. July 2015, pp. 1-18, 2017.

[12] O. Ezinwanne, F. Zhongwen, and L. Zhijun, "Energy Performance and Cost Comparison of MPPT Techniques for Photovoltaics and other Applications," Energy Procedia, vol. 107, pp. 297-303, Feb. 2017.

[13] H. Islam et al., "Performance Evaluation of Maximum Power Point Tracking Approaches and Photovoltaic Systems," Energies, vol. 11, no. 2, p. 365, 2018.

[14] M. Kamran, M. Mudassar, M. Rayyan Fazal, M. Usman Asghar, M. Bilal, and R. Asghar, "Implementation of improved Perturb \&amp; Observe MPPT technique with confined search space for standalone photovoltaic system," 2018.

[15] R. John, S. S. Mohammed, and R. Zachariah, "Variable step size Perturb and observe MPPT algorithm for standalone solar photovoltaic system," Proc. 2017 IEEE Int. Conf. Intell. Tech. Control. Optim. Signal Process. INCOS 2017, vol. 2018-Febru, pp. 1-6, 2018.

[16] L. Piegari et al., "Optimized Adaptive Perturb and Observe Maximum Power Point Tracking Control for Photovoltaic Generation," Energies, vol. 8, no. 5, pp. 3418-3436, Apr. 2015.

[17] A. Loukriz, M. Haddadi, and S. Messalti, "Simulation and experimental design of a new advanced variable step size Incremental Conductance MPPT algorithm for PV systems," ISA Trans., vol. 62, pp. 30-38, 2016.

[18] K. Soon Tey and S. Mekhilef, "Modified incremental conductance MPPT 
algorithm to mitigate inaccurate responses under fast-changing solar irradiation level," Sol. Energy, vol. 101, pp. 333-342, 2014.

[19] B. Bendib, H. Belmili, and F. Krim, "A survey of the most used MPPT methods: and advanced algorithms applied for photovoltaic systems," Renew. Sustain. Energy Rev., vol. 45, pp. 637-648, 2015.

[20] E. Kabalci, "Maximum Power Point Tracking (MPPT) Algorithms for Photovoltaic Systems," Springer, Cham, 2017, pp. 205-234.

[21] J. Kivimaki, S. Kolesnik, M. Sitbon, T. Suntio, and A. Kuperman, "Revisited Perturbation Frequency Design Guideline for Direct Fixed-Step Maximum Power Point Tracking Algorithms," IEEE Trans. Ind. Electron., vol. 64, no. 6, pp. 46014609, 2017.

[22] M. A. Elgendy, D. J. Atkinson, and B. Zahawi, "Experimental investigation of the incremental conductance maximum power point tracking algorithm at high perturbation rates," IET Renew. Power Gener., vol. 10, no. 2, pp. 133-139, Feb. 2016.

[23] J. Ahmed and Z. Salam, "An improved perturb and observe (P\&amp;O) maximum power point tracking (MPPT) algorithm for higher efficiency," Appl. Energy, vol. 150, pp. 97-108, 2015.

[24] K. K, P. K. R, and R. B. N, "Design and Analysis of Modified Single P\&amp;O MPPT Control Algorithm for a Standalone Hybrid Solar and Wind Energy Conversion System," Gazi Univ. J. Sci., vol. 30, no. 4, pp. 296-312.

[25] R. Alik and A. Jusoh, "Modified Perturb and Observe (P\&amp;O) with checking algorithm under various solar irradiation," Sol. Energy, vol. 148, pp. 128-139, May 2017.

[26] A. Akbar Ghassami, S. Mohammad Sadeghzadeh, and A. Soleimani, "A high performance maximum power point tracker for PV systems," Int. J. Electr. Power Energy Syst., vol. 53, pp. 237-243, 2013.

[27] J. Ahmed, J. Ahmed, S. Member, and Z. Salam, "A Modified P \& O Maximum Power Point Tracking Method with Reduced Steady State Oscillation and Improved Tracking Efficiency," IEEE Trans. Sustain. Energy, vol. 3029, no. January, pp. 1-10, 2016.

[28] N. Abdullahi, C. Saha, and R. Jinks, "Modelling and performance analysis of a silicon PV module," vol. 033501, pp. 1-11, 2017.

[29] C. W. T. C. W. Tan, T. C. Green, and C. a. Hernandez-Aramburo, "Analysis of perturb and observe maximum power point tracking algorithm for photovoltaic applications," 2008 IEEE 2nd Int. Power Energy Conf., no. PECon 08, pp. 237242, 2008

[30] M. A. Abdourraziq, M. Ouassaid, M. Maaroufi, and S. Abdourraziq, "Modified P \& O MPPT Technique for Photovoltaic Systems," Ieee, no. October, pp. 20-23, 2013.

[31] A. Belkaid, I. Colak, and O. Isik, "Photovoltaic maximum power point tracking under fast varying of solar radiation," 2016.

[32] A. M. Eltamaly, H. M. H. Farh, and M. F. Othman, "A novel evaluation index for the photovoltaic maximum power point tracker techniques," Sol. Energy, vol. 174, pp. 940-956, Nov. 2018.

[33] K. Ishaque, Z. Salam, and G. Lauss, "The performance of perturb and observe and incremental conductance maximum power point tracking method under dynamic weather conditions," Appl. Energy, vol. 119, pp. 228-236, 2014.

[34] N. Femia, G. Petrone, G. Spagnuolo, M. Vitelli, Power Electronics and 
Control Techniques for Maximum Energy Harvesting in Photovoltaic Systems, USA, FL, Boca Raton:CRC, 2013.

[35] H. M. H. Farh, A. M. Eltamaly, and M. F. Othman, "Hybrid PSO-FLC for dynamic global peak extraction of the partially shaded photovoltaic system," 2018. 